\section{BEHAVIOUR OF PIGS}

T the course of experimental work of a nutritional 1 and physiological character at the National Institute for Research in Dairying, R. Braude has noted some interesting features about the behaviour of pigs (Bull. Animal Behaviour, No. 6 ; January 1948). These observations have been recorded without any attempt to fit them into the framework of existing theories of behaviour, and, in the words of Dr. E. S. Russell, they merely "serve to illustrate what is the most characteristic feature of behaviour, namely, that the animal tries or strives to do something specific, that it seems to achieve some end, to satisfy some need".

On one occasion a wooden block resembling a sow with two rows of rubber teats fitted at the approximate spot was put into the farrowing pen. It was placed as near as possible to a sow which was farrowing. Not one of the fourteen piglets born on this occasion showed any interest whatsoever in the dummy teats, while all were keenly interested in the real teats, and as usual fought for access to them.

Another observation concerns the behaviour of piglets in suckling usually from the same teat. Donald has stated that "this ability must be founded mainly on sight, with some capacity to recognize the foel of a nipple playing a secondary part. Hearing may be disregarded, and so may a sense of smell, for pigs placed with a foster mother will, if they are able, take up the position they had on their original mother." From the start it seems to be of importance to the piglets to obtain a correct position on the udder. The quality of the teats varies to such an extent that it is not surprising that in the early stages of suckling the piglets are prepared to fight for access to the good ones and those successful occupy them permanently. The resultant growth-rate of the victors indicates the importance of this selection. With a small litter the best teats are soon discovered and continue to be sucked throughout lactation, while the poor ones are completely abandoned, and gradually dry off. With large litters some of the piglets never secure the chance of settling down at a good teat, and this fact seems to be mainly responsible for the usual one or two 'runts' in a large litter.

The effects of massaging the udder by the piglets just before the actual suckling have also been observed. With cows, the composition of the milk obtained depends on whether the udder has been previously stimulated or not, while in pigs there is evidence that the milk obtained by draining it off is only half as rich in fat as that obtained by the young pigs suckling. That the controlling factor is of a hormonal nature has been confirmed by Kon, Thompson and Braude, and by means of 'Pitocin', a proprietary extract from the posterior lobe of the pituitary which contains the oxytocic principle, it is now possible to milk a sow in much the same way as a cow. To milk the sow after treatment with 'Pitocin' the sow' has to be roped. Here an interesting aspect of behaviour is shown. It is well known that a sow will struggle against roping and that once caught she will try to get rid of the rope. What she usually does, however, is to pull back with all her strength, and by so doing makes the noose only more secure. On the other hand, if she were to walk forward-and there is nothing to stop her doing so-the effectiveness of roping would be completely lost. For some unknown reason this never occurs. The explanation that she can see the holder of the rope in front of her and tries to back away from him has proved to be untrue. The holder of the rope has been concealed and two people have been placed behind the sow. Those behind have had to push with all their strength to make the sow step forward.

Other observations show that, once a sow has done a long walk to the piggery where the boar is kept, she seems to learn the route and needs little guiding on subsequent occasions. Sows usually keep to the road and are careful when leaving it, making sure that the path they are taking is safe for them.

Except when mating, two grown pigs brought together will fight each other until one establishes a complete supremacy; sometimes even death may result. Mixing young weaners from different litters invariably results in a fight; but these soon settle down together. On the whole, however, pigs like company, and cases have been known when separated pigs have had to be brought back to their mates because "they went in seclusion on what amounted to a hunger strike". It is also known that a strong pig will keep a weaker one away from the food trough, while in the pen the favourite place for sleeping is occupied by the stronger. On occasions when two lots of pigs are mixed together in one pen, the usual fight is followed by the relegation of the defeated to the dunging passage.

That pigs quickly become accustomed to new routines which have to be introduced into an experi. mental piggery is shown by the following. Pigs have to be weighed at frequent intervals, sometimes daily and at least once weekly. At first it is difficult to get them into the weighing pen; but, after a few times, they walk into it of their own accord as soon as the door of the weighing pen is opened. A clearer example of a conditioned reflex is quoted by Braude from Denmark. There, a certain pigman arrives at his piggery in the morning and, as his first job, rings a heavy bell. This was a signal for all the pigs in that piggery to get up and go out into the dunging passage to defecate and urinate. The procedure was repeated as regularly in the afternoon, and this practice kept the piggery clean.

Information on the feeding habits of pigs has also been collected and shows the pig is a selective feeder. The now well-known story of its liking for copper is re-told, together with further evidence which has been collected by experimental inquiry.

\section{NATURE AND CONSTITUTION OF GLASS}

$A^{T}$ $T$ the recent joint meeting of the International Commission on Glass and the Society of Glass Technology, a symposium was arranged having as a general title "Some Aspects of the Nature and Con. stitution of Glass". Fifteen papers, presented by American, British and Continental investigators, ranged widely over the subject and raised, in each of three sessions, lively and sustained discussions.

In an introduction to the series of papers, Prof. W. E. S. Turner reviewed the important historical developments of the subject and referred to the place of theory in glass technology. Whereas for some forty years or more Tammann's theory of glass as a supercooled liquid had done much to account for many of the properties of glasses, greater insistence was now being laid, as indicated in the paper "Solid 